$\begin{array}{ll}\text { Research Square } & \begin{array}{l}\text { Preprints are preliminary reports that have not undergone peer review. } \\ \text { They should not be considered conclusive, used to inform clinical practice, } \\ \text { or referenced by the media as validated information. }\end{array}\end{array}$

\title{
India's Performance in Controlling Visceral Leishmaniasis as Compared to Brazil Over Past Three Decades: Findings From Global Burden of Disease Study
}

DEEPAK DHAMNETIYA ( $\sim$ drdeepakdhamnetiya@gmail.com )

Dr Baba Saheb Ambedkar Medical College and Hospital https://orcid.org/0000-0002-5634-3315

\section{Ravi Prakash Jha}

Dr Baba Saheb Ambedkar Medical College and Hospital

Shalini .

Lady Hardinge Medical College

Krittika Bhattacharyya

University of Calcutta

\section{Original Article}

Keywords: Visceral Leishmaniasis, kala-azar, incidence, prevalence, mortality, DALY

Posted Date: February 3rd, 2021

DOI: https://doi.org/10.21203/rs.3.rs-160813/v1

License: @ (i) This work is licensed under a Creative Commons Attribution 4.0 International License. Read Full License

Version of Record: A version of this preprint was published at Journal of Parasitic Diseases on March 18th, 2021. See the published version at https://doi.org/10.1007/s12639-021-01375-0. 


\section{Abstract}

Visceral leishmaniasis $(\mathrm{VL})$ is a neglected tropical disease which contributes to the mortality and morbidity significantly in India and Brazil. This study was planned to compare the trends of incidence, prevalence, death and disability-adjusted life years (DALY) of VL burden in India and Brazil from 1990 to 2019 using Global burden of disease study (GBD) data. The metrics are presented as age-standardized rates per 100,000 inhabitants with their respective uncertainty intervals (95\%UI) and relative percentages of change. The decline in the Incidence rate is more in case of India (16.82 cases per 100,000 in 1990 to 0.60 cases in 2019) as compared to Brazil (3.12 cases per 100,000 in 1990 to 2.65 cases in 2019). The annualized rate of change in number of prevalent cases for India is -0.95 ( $95 \% \mathrm{UI},-0.98$ to -0.91$)$ whereas for Brazil it is -0.06 (95\% $\mathrm{UI},-0.41$ to 0.52$)$. The annualized rate of change in number of DALY for India is -0.94 (95\% UI, -0.96 to -0.92$)$ whereas for Brazil it is $-0.09(95 \% \mathrm{UI},-0.25$ to 0.28 ). The annualized rate of change in number of deaths for India is -0.93 (95\% UI, -0.95 to -0.92$)$ whereas for Brazil it is increasing i.e. $0.04(95 \% \mathrm{UI},-0.12$ to 0.51$)$. India achieves significant reduction in the age standardized incidence, prevalence, mortality and DALY of VL as compare to Brazil during the period of 1990 to 2019. A multi-centric study is required to assess bottleneck in the existing strategies of VLSCP in Brazil.

\section{Introduction}

Visceral Leishmaniasis (VL) or Kala-azar is a neglected tropical disease which contributes to the mortality and morbidity significantly in India and Brazil (Sundar et al. 2012). In India, it is caused by parasite called Leishmania donovani and transmitted from one person to another by the bite of infected female sand fly known as Phlebotomus argentipes (Muniaraj 2014). In the Americas, the etiological agent is the protozoan Leishmania infantum, which is transmitted through the bite of the phlebotomine Lutzomyia longipalpis, with dogs being its main urban reservoir (Lainson et al. 1978).

Annually 50000 to 90000 new cases of VL occur globally, among them only 25 to $45 \%$ reported to World Health Organization (WHO). According to the outbreak and mortality potential, VL remains one of the top parasitic diseases. Both India and Brazil have found their places in the list of 10 countries which have reported more than 95\% of new cases to WHO in 2018 (WHO factsheet 2020). According to the World Bank, India and Brazil belong to lower-middle income economies and upper-middle income economies respectively. In 2017, expenditure of India on health was 3.53\% of the Gross Domestic Product, whereas Brazil's health expenditure in the same year was $9.45 \%$ (World Bank 2020). If we look at the state-wise scenario, Kala-azar is endemic in northern and eastern States of India namely Bihar, Jharkhand, Uttar Pradesh and West Bengal. 54 districts of these four states have attained endemic region status for kala-azar and few other districts have reported occasional cases as well. The latest estimated figure is 165.4 million population which is under the risk of developing kala-azar in these 4 states combined (MoHFW, Gol 2020). In the Americas, 12 countries have registered the presence of VL. 90\% of these cases are reported in Brazil alone with the case fatality rate being around 7\% (da Rocha et al 2018). Until 1990, only the Kala-azar affected and worst hit States used to carry out Kala-azar control activities in India. As the incidence of Kala-azar was soaring in parts of India, the Gol launched a centrally sponsored “Kala-azar Control Program” during 1991 (Kishore et al. 2006). In 2000, the program was further reviewed by an expert committee chaired by the director general of health services, and recommendation was made to incorporate the elimination of Kala-azar from India in the National Health Policy (Thakur et al. 2009) by renaming the same as "National Kala-azar Elimination Programme". As we shifted our focus to review the existing policies of Brazil, we acknowledged the launch of The Brazilian Visceral Leishmaniasis Surveillance and Control Programme (VLSCP) strategies in early 90 's. This strategy included a considerable number of public health measures like canine serological analysis followed by euthanasia of seropositive dogs, together with chemical control of the vector and diagnostic techniques, early diagnosis and treatment of human cases, and population awareness (da Rocha et al 2018). From the data, it is evident that both the countries (India and Brazil) had significant burden of kala-azar in early 1990s and they have given special emphasis on the control of kala-azar in their country. This study was planned to compare the trends of Visceral Leishmaniasis burden in India and Brazil from 1990 to 2019 using Global burden of disease study data.

\section{Materials And Methods}


The GBD study offers a powerful resource to understand the changing health challenges facing people across the world in the 21st century. Led by the Institute for Health Metrics and Evaluation (IHME), the GBD study is the most comprehensive worldwide observational epidemiological study to date. By tracking progress within and between countries GBD provides an important tool to inform clinicians, researchers, and policy makers, promote accountability, and improve lives worldwide.

Over the past 2 decades, the IHME has developed a methodology to quantify the burden of diseases, injuries, and risk factors for informing health program and policy-making. GBD regularly provides comparable estimates of the key indicators of disease burden assessment, including the incidence prevalence, mortality and DALYs rate of Visceral Leishmaniasis. The present study utilized the GBD 2019 database to systematically summarize, analyze and compare the Incidence, Prevalence, mortality and DALYs of Visceral Leishmaniasis and its changes since 2019 for India and Brazil.

\section{Data sources}

GBD 2019 estimated each epidemiological quantity of interest-incidence, prevalence, mortality, years lived with disability (YLDs), years of life lost (YLLs), and disability-adjusted life-years (DALYs)-for 23 age groups; males, females, and both sexes combined; and 204 countries and territories that were grouped into 21 regions and seven super-regions (GBD 2019 Diseases and Injuries Collaborators 2020). Total of 59 different data sources has been used to model the cause of death and 62 different data sources to model both cause of death and disability estimates for Visceral Leishmaniasis in India. The key sources of data to model the cause of death due to Visceral Leishmaniasis in India included Medical certification of cause of deaths of the country and of various states, India vital statistics report, WHO Global Health Observatory reported cases, other surveys on cause of death and published scientific articles (GBD 2019 Diseases and Injuries Collaborators 2020).

Total of 68 different data sources has been used to model the cause of death and 70 different data sources to model both cause of death and disability estimates for Visceral Leishmaniasis in Brazil. The key sources of data to model the cause of death due to Visceral Leishmaniasis in Brazil included Brazil Information system for notifiable disease for various years, Brazil mortality information system, Brazil WHO Leishmaniasis country profile, WHO Global Health Observatory reported cases, other surveys on cause of death and published scientific articles (GBD 2019 Diseases and Injuries Collaborators 2020).

Cause-specific death rates and cause fractions were calculated using the Cause of Death Ensemble model (CODEm) and spatiotemporal Gaussian process regression. A detailed description of CODEm is reported elsewhere (Lozano et al. 2012, Foreman et al. 2012, Murray et al. 2012, Murray et al 2014). Cause-specific deaths were adjusted to match the total all-cause deaths calculated as part of the GBD population, fertility, and mortality estimates. Deaths were multiplied by standard life expectancy at each age to calculate YLLs. A Bayesian meta-regression modelling tool, DisMod-MR 2.1, was used to ensure consistency between incidence, prevalence, remission, excess mortality, and cause-specific mortality for most causes. Prevalence estimates were multiplied by disability weights for mutually exclusive sequelae of diseases and injuries to calculate YLDs. Uncertainty intervals (Uls) were generated for every metric using the 25th and 975th ordered 1000 draw values of the posterior distribution (GBD 2019 Diseases and Injuries Collaborators 2020).

We have included only a special category of Leishmaniasis in our paper i.e. Visceral Leishmaniasis. Data sources for the incidence rate, prevalence, Death and DALYs of Visceral Leishmaniasis was extracted from an online tool produced by the IHME which is publicly available called the GHDx (Global Health Data Exchange) query tool (http://ghdx.healthdata.org/gbd-resultstool) (Global Burden of Disease Collaborative Network 2020) Percentage change and annualized rate of change of the estimates is reported.

\section{Results}

Overall there is decrease in the Incidence rate of Visceral Leishmaniasis for both India and Brazil, however the decline is more in case of India (16.82 cases per 100,000 in 1990 to 0.60cases in 2019) as compared to Brazil (3.12 cases per 100,000 in 1990 to 2.65 cases in 2019) [Table 1]. The overall percentage decrease in Incidence rate per 100,000 from 1990 to 2019 in case of India and Brazil is $2703.33 \%$ and $17.74 \%$ respectively. The total number of incident cases due to Visceral Leishmaniasis in India declined from 174821 cases in 1990 to 8145 cases in 2019; and for Brazil, it decreased slightly from 5275 cases in 1990 to 
4983 cases in 2019 . The annualized rate of change in number of incident cases for India is -0.95 ( $95 \% \mathrm{Ul},-0.98$ to -0.91$)$ whereas for Brazil it is -0.06 ( $95 \% \mathrm{Ul},-0.41$ to 0.52 ).

Overall there is decrease in the Prevalence rate of Visceral Leishmaniasis for both India and Brazil, However the decline is more in case of India (4.20 cases per 100,000 in 1990 to 0.15 cases in 2019) as compared to Brazil (0.78 cases per 100,000 in 1990 to 0.66 cases in 2019). The overall percentage decrease in prevalence rate per 100,000 from 1990 to 2019 in case of India and Brazil is $2700.00 \%$ and $18.18 \%$ respectively. The total number of prevalent cases due to Visceral Leishmaniasis in India declined from 43705 cases in 1990 to 2036 cases in 2019; and for Brazil it decreased slightly from 1319 cases in 1990 to 1246 cases in 2019. The annualized rate of change in number of prevalent cases for India is -0.95 ( $95 \% \mathrm{UI},-0.98$ to -0.91 ) whereas for Brazil it is -0.06 (95\% UI, -0.41 to 0.52$)$.

There is decrease in the DALYs rate of Visceral Leishmaniasis for both India and Brazil, However the decline is more in case of India (124.11 DALY per 100,000 in 1990 to 5.88 DALY in 2019) as compared to Brazil (41.55 DALY per 100,000 in 1990 to 33.63 DALY in 2019). The overall percentage decrease in DALY per 100,000 from 1990 to 2019 in case of India and Brazil is 2010.71\%and 23.55\%respectively. The total number of DALY due to Visceral Leishmaniasis in India declined from 1274643 in 1990 to 79733 in 2019; and for Brazil it decreased slightly from 70141 in 1990 to 64095 in 2019. The annualized rate of change in number of DALY for India is -0.94 ( $95 \% \mathrm{UI},-0.96$ to -0.92$)$ whereas for Brazil it is -0.09 (95\% $\mathrm{UI},-0.25$ to 0.28 ).

There is decrease in the death rate of Visceral Leishmaniasis for both India and Brazil, However the decline is more in case of India (1.97 deaths per 100,000 in 1990 to 0.09 deaths in 2019) as compared to Brazil (0.63 deaths per 100,000 in 1990 to 0.51 deaths in 2019). The overall percentage decrease in death rate per 100,000 from 1990 to 2019 in case of India and Brazil is $2088.89 \%$ and $23.53 \%$ respectively. The total number of death due to Visceral Leishmaniasis in India declined from 18068 deaths in 1990 to 1206 deaths in 2019; whereas in Brazil it increased from 992 deaths in 1990 to 1035 deaths in 2019. The annualized rate of change in number of deaths for India is $-0.93(95 \% \mathrm{UI},-0.95$ to -0.92$)$ whereas for Brazil it is increasing i.e. $0.04(95 \%$ UI, -0.12 to 0.51$)$ [Table 1].

Age Standardized Incidence rates in India continuously fall from 1990 (16.81cases per 100,000) to 2000 (2.34 cases per 100,000), after that it increased till 2005 (4.34 cases per 100,000) and then gradually show declining trends till 2019 (0.60 cases per 100,000). In case of Brazil, incidence rates show a constant trend with slight variation and reached to 2.65 cases in 2019 from 3.12 in 1990 [Fig 1].

Age Standardized prevalence rate in India continuously fall from 1990 (4.20cases per 100,000) to 2000 (0.59 cases per 100,000), after that it increased till 2005 (1.08 cases per 100,000) and then gradually show declining trends till 2019 ( 0.15 cases per 100,000). In case of Brazil, incidence rates shows a constant trend with slight variation and reached to 0.66 cases per 100,000 in 2019 from 0.78 cases per 100,000 in 1990 [Fig 2].

The age-standardized mortality rate due to visceral Leishmaniasis in India was quite high in 1990 (1.97 deaths per 100,000 population) as compared to Brazil (0.63 deaths). In India it declined continuously till 2001; and comes below the mortality rate of Brazil in 1995. After 2001, it increased continuously till 2007 in India, where it reaches 0.65 deaths per 100,000 populations similar to the mortality rate of Brazil for the same year. However after 2007, the mortality rate in India continuously decline and reached to 0.089 deaths per 100,000 populations. From 1990 to 2019, Brazil has seen a slight increase or decrease in the mortality rate and it reached to 0.51 deaths in 2019 [Fig 3].

A similar trend as seen in case of age-standardized mortality rates have been observed for age standardized DALY rate for both India and Brazil. Age Standardized DALY rates in India continuously fall from 1990 (124.1 DALY per 100,000) to 2001 (19.83 DALY per 100,000), after that it increased till 2007 (42.44 DALY per 100,000) and then gradually show declining trends till 2019 (5.88 DALY per 100,000). In case of Brazil, a slight variation in DALY rates over the years has been seen and it reached to 33.63 in 2019 from 41.55 in 1990 [Fig 4].

In India as well as Brazil, higher age standardized incidence, prevalence, mortality and DALY rates of Visceral Leishmaniasis is reported in males vis-à-vis females for all years i.e. 1990 to 2019. India has reduced gender based gap in the age standardized 
incidence, prevalence, mortality and DALY rates since past one decade and maintained approximately equal rates in males as well as females since past six years, whereas Brazil has not able to reduce gender based gap in the age standardized incidence, prevalence, mortality and DALY rates since past three decades [Fig 5]. In India as well as Brazil, higher incidence, prevalence, mortality and DALY rates of Visceral Leishmaniasis is reported in the age groups ( $<1$ year, 1 to 4 years, 5 to 9 years and 10 to 14 years) as compared to the age groups of 15 years and above [Fig 6].

\section{Discussion}

We have compared the trends of kala-azar burden in India and Brazil from 1990 to 2019 using Global burden of disease study data.

\section{Control of Visceral Leishmaniasis in India}

Present study showed that Age Standardized Incidence rates in India continuously fall from $1990(16.81$ cases per 100,000) to 2000 ( 2.34 cases per 100,000), after that it increased till 2005 (4.34 cases per 100,000) and then gradually show declining trends till 2019 ( 0.60 cases per 100,000). Same trend has been reported for age standardized prevalence rates. This trend may be attributed to government initiative of DDT spray in endemic areas. In 1992, the DDT spray was started second time and continued till 1995 and the effect was persistent up to year 2000 (Thakur et al. 2007). No rounds of DDT spray were carried out until 2006 (Mubayi et al. 2010), Then again, in 2007 DDT spray was started. The effect of DDT may persist from 3 years to as long as up to 7 years with the intensity and duration of spray (Thakur et al. 2007). Another attributable factor might be development of resistance against DDT in phlebotomus argentipes in some endemic areas (Singh et al. 2001, Dhiman et al. 2003).

In India age standardized mortality rates declined continuously till 2001, after that it increased continuously till 2007. However after 2007, the mortality rate in India continuously decline and reached to 0.089 deaths per 100,000 populations. Similar trend has been reported for age standardized DALY rates. This declining trend may be attributed to government's timely change in the diagnostic as well as treatment modalities of VL. High mortality rate in early 1990s may be attributed to decrease in the cure rate of sodium stibogluconate (SbV) to $81 \%$ in late 1980 s (Thakur et al. 1991) and the pentamidine to $70-75 \%$ (Berman et al. 1997). Because of increase in resistance to two first line antileishmanisis drugs i.e. SbV and pentamadine, amphotericin $B$ and liposomal amphotericin B were started to be used for the treatment of VL in mid 1990s. Amphotericin B had cure rate of 99$100 \%$ (Thakur et al. 1993), this leads to continuous decline in mortality rate of VL. Increase in the mortality during the year 2001 to 2007 may be attributed to HIV-VL co-infection. The probability of death or treatment failure of VL in HIV co-infection was estimated to be $67 \%$ (Mathur et al. 2006) and 69.8\% after 2 year of completion of treatment. HIV infection dramatically increases the risk of progression from asymptomatic infection to VL disease and VL accelerates HIV disease progression (Sinha et al. 2011).

The 4 A's named as Accessibility, Affordability, Availability and Awareness remained the key characteristics where India did sound progress in case of Kala-azar control strategies and execution over the past three decades. During the study period 1990 to 2019 , comprehensive public health measures and strategies like integrated vector management (IVM) and effective as well as efficient interventions like Indoor residual spray, Personal prophylaxis, micro-environmental management etc were found to contribute largely to the continuous decline in the incidence, prevalence and mortality due to VL. Apart from that, the introduction of Rapid Diagnosis test Kits for the prompt diagnosis of $\mathrm{VL}$ even in areas with limited transportation facilities could be considered as the major milestone in fighting the disease. Inclusion of relatively safe oral drugs like Miltefosine for the treatment of VL helped to keep the infection in control. The provision of incentives to VL patients as well as peripheral health workers like ASHA raised the awareness and thus contributed to the decline in new cases in a significant manner. New initiatives like "Kala-azar Mitra (Friend)' were started in which past treated patients act as a communicator for providing information to the health facilities or health worker regarding new Kala-azar resembling patient (MoHFW, Gol 2015).

\section{Control of Visceral Leishmaniasis in Brazil}


In this study constant trend with slight variation has been reported in the age standardized incidence rates of VL which changes from 3.12 cases per 100,000 in 1990 to 2.65 cases in 2019 . Similar trend were reported in age standardized prevalence rates of VL which changes from 0.78 cases per 100,000 in 1990 to 0.66 cases in 2019. Brazil has revised VL control strategy in early 1990s and launched The Brazilian Visceral Leishmaniasis Surveillance and Control Programme (VLSCP). The substantially poor impact and penetration of interventions were quite eminent due to the low sensitivity of the diagnostic tests, the long delay between diagnosis and culling, and the low acceptance of culling by dog owners. Different studies have concluded that the treatment of infected dogs cannot be an effective long-term strategy as relapses are quite frequent in such cases, and same dogs become infectious again within a short period of time (Alvar et al. 1994). A recent study conducted by Werneck et al recommended the modification of the existing delivery of interventions according to the different transmission scenarios, along with the existing strategies of VL control program, while preferably targeting the areas at highest risk. They also emphasized on collective and efficient efforts to solve operational barriers to the adequate implementation of preventive measures (Werneck et al. 2014). A relevant quasi-experimental study conducted by da Rocha et al on effectiveness of VLSCP pointed out several limitations in the strategies adopted by the VLSCP in the sense that the control interventions were not successful enough in interrupting L. infantum transmission, especially in urban areas (da Rocha et al. 2018).

\section{Conclusion}

Visceral leishmaniasis is a public health problem in India as well as in Brazil. Both the countries have revised their strategies in early 1990s to control VL. India achieves significant reduction in the age standardized incidence, prevalence, mortality and DALY of VL as compare to Brazil during the period of 1990 to 2019. A multi-centric study is required to assess bottleneck in the existing strategies of VLSCP in Brazil. India's experience can be utilized for the further reduction in the burden of VL in Brazil.

\section{Declarations}

Acknowledgements: We thank the Institute for Health Metrics and Evaluation (IHME) and the University of Washington for providing the GBD estimates.

Funding: None

Conflicts of interest/Competing interests: None declared

Availability of data and material: Data is publicly available on http://ghdx.healthdata.org/gbd-results-tool and free to use

Code availability: None

Authors' contributions: Conceptualization: DD, RPJ, Shalini, KB; Formal analysis: DD, RPJ, KB; Methodology: DD, RPJ, KB; Writingoriginal draft: DD, RPJ, Shalini, KB; Writing-review \& editing: DD, RPJ, Shalini, KB

\section{References}

Alvar J, Molina R, San Andre's M, Tesouro M, Nieto J, Vitutia M, et al (1994) Canine leishmaniasis: clinical, parasitological and entomological follow-up after chemotherapy. Ann Trop Med Parasitol 88: 371-378.

Berman JD (1997) Human leishmaniasis: Clinical, diagnostic, and chemotherapeutic developments in the last 10 years. Clin Infect Dis 24:684-703.

da Rocha ICM, Dos Santos LHM, Coura-Vital W, da Cunha GMR, Magalhães FDC, da Silva TAM (2018) Effectiveness of the Brazilian Visceral Leishmaniasis Surveillance and Control Programme in reducing the prevalence and incidence of Leishmania infantum infection. Parasites \& Vectors 11, 586.

Dhiman RC, Raghavendra K, Kumar V, Kesari S, Kishore K (2003) Susceptibility status of Phlebotomusargentipes to insecticide in districts Vaishali and Patna. J Commun Dis. 35:49-51. 
Foreman KJ, Lozano R, Lopez AD, Murray CJ (2012) Modeling causes of death: an integrated approach using CODEm. Popul Health Metr 10:1.

GBD 2019 Diseases and Injuries Collaborators. Global burden of 369 diseases and injuries in 204 countries and territories, 1990-2019: a systematic analysis for the Global Burden of Disease Study 2019 (2020). Lancet 396: 1204-22.

Global Burden of Disease Collaborative Network. Global Burden of Disease Study 2019 (GBD 2019) Results. Seattle, United States: Institute for Health Metrics and Evaluation (IHME), (2020). Available from http://ghdx.healthdata.org/gbd-results-tool

Kishore K, Kumar V, Kesari S, Dinesh DS, Kumar AJ, Das P, et al (2006) Vector control in leishmaniasis. Indian J Med Res 123:467-72.

Lainson R, Shaw JJ (1978) Epidemiology and ecology of leishmaniasis in Latin-America. Nature 273:595-600.

Lozano R, Naghavi M, Foreman K, Lim S, Shibuya K, Aboyans V, et al (2012) Global and regional mortality from 235 causes of death for 20 age groups in 1990 and 2010: a systematic analysis for the Global Burden of Disease Study 2010. Lancet 380:2095-128.

Mathur P, Samantaray JC, Vajpayee M, Samanta P (2006) Visceral leishmaniasis/human immunodeficiency virus co-infection in India: The focus of two epidemics. J Med Microbiol 55:919-22.

Mubayi A, Castillo-Chavez C, Chowell G, Kribs-Zaleta C, Ali Siddiqui N, Kumar N, et al (2010) Transmission dynamics and underreporting of Kala-azar in the Indian state of Bihar. J TheorBiol 262:177-85.

Muniaraj M (2014) The lost hope of elimination of Kala-azar (visceral leishmaniasis) by 2010 and cyclic occurrence of its outbreak in India, blame falls on vector control practices or co-infection with human immunodeficiency virus or therapeutic modalities? Tropical parasitology 4(1):10-9.

Murray CJ, Ezzati M, Flaxman AD, Lim S, Lozano R, Michaud C, et al (2012) GBD 2010: design, definitions, and metrics. Lancet 380:2063-6.

Murray CJ, Ortblad KF, Guinovart C, Lim SS, Wolock TM, Roberts DA, et al (2014) Global, regional, and national incidence and mortality for HIV, tuberculosis, and malaria during 1990-2013: a systematic analysis for the Global Burden of Disease Study 2013. Lancet 384:1005-70.

National Vector Borne Disease Control Programme, Ministry of Health \& Family Welfare, Gol Operational Guidelines on KalaAzar (Visceral Leishmaniasis) Elimination In India - 2015. Available at https://nvbdcp.gov.in/Doc/opertional-guideline-KA2015.pdf last accessed on 5 January, 2021.

National Vector Borne Disease Control Programme (NVBDCP), Ministry of Health \& Family Welfare, Gol What is the extent of problem of kala-azar in India? (2020). Available at https://nvbdcp.gov.in/index4.php?lang=1\&level=0\&linkid=474\&lid=3749 last accessed on 12 December 2020.

Singh R, Das RK, Sharma SK (2001) Resistance of sandflies to DDT in Kala-azar endemic districts of Bihar in India. Bull World Health Organ 79:793.

Sinha PK, van Griensven J, Pandey K, Kumar N, Verma N, Mahajan R, et al (2011) Liposomal amphotericin B for visceral leishmaniasis in human immunodeficiency virus-coinfected patients: 2-year treatment outcomes in Bihar, India. Clin Infect Dis 53:e91-8.

Sundar S, Chakravarty J (2012) Recent advances in the diagnosis and treatment of kala-azar. Natl Med J India 25:85-91.

Thakur CP, Kumar M, Pandey AK (1991) Evaluation of efficacy of longer durations of therapy of fresh cases of kala-azar with sodium stibogluconate. Indian J Med Res 93:103-10. 
Thakur CP, Sinha GP, Pandey AK, Barat D, Sinha PK (1993) Amphotericin B in resistant kala-azar in Bihar. Natl Med J India 6:57-60.

Thakur CP (2007) A new strategy for elimination of kala-azar from rural Bihar. Indian J Med Res 126:447-51.

Thakur CP, Meenakshi Thakur AK, Thakur S (2009) Newer strategies for the kala-azar elimination programme in India. Indian J Med Res 129:102-4.

The World Bank (2020). Current health expenditure (\% of GDP). Available at https://data.worldbank.org/indicator/SH.XPD.CHEX.GD.ZS?name_desc=false last accessed on 11 December 2020.

The World Bank (2020). World Bank Country and Lending Groups. Available at https://datahelpdesk.worldbank.org/knowledgebase/articles/906519-world-bank-country-and-lending-groups last accessed on 11 December 2020.

Werneck GL, Costa CHN, de Carvalho FAA, Pires e Cruz MdS, Maguire JH, et al. (2014) Effectiveness of Insecticide Spraying and Culling of Dogs on the Incidence of Leishmaniainfantum Infection in Humans: A Cluster Randomized Trial in Teresina, Brazil. PLoSNegl Trop Dis 8(10): e3172.

World Health Organization. Geneva: Leishmaniasis-Fact sheet Updated on March 2020. Available at https://www.who.int/news-room/fact-sheets/detail/leishmaniasis last accessed on 11 December 2020.

\section{Tables}

Table 1: Mortality, incidence, DALY and prevalence rates of visceral Leishmaniasis, percentage change and annualized rates of change (95\% UI) between 1990 and 2019 for India and Brazil 


\begin{tabular}{|c|c|c|c|c|c|c|c|c|c|}
\hline \multirow[t]{2}{*}{ Measure } & \multirow[t]{2}{*}{ Metric } & \multicolumn{2}{|c|}{ \# or rate $(95 \%$ UI) 1990} & \multicolumn{2}{|c|}{ \# or rate (95\% UI) 2019} & \multicolumn{2}{|l|}{$\%$ Change } & \multicolumn{2}{|c|}{ ARC (95\% UI) } \\
\hline & & India & Brazil & India & Brazil & India & Brazil & India & Brazi \\
\hline \multirow[t]{2}{*}{ Incidence } & Number & $\begin{array}{l}174821.93 \\
(110890.27- \\
252628.84)\end{array}$ & $\begin{array}{l}5274.99 \\
(3900.33- \\
6929.15)\end{array}$ & $\begin{array}{l}8145.48 \\
(4719.26- \\
12830.38)\end{array}$ & $\begin{array}{l}4982.85 \\
(3391.81- \\
7179.34)\end{array}$ & -2046.24 & -5.86 & $\begin{array}{l}-0.95 \\
(-0.98 \\
\text { to } \\
-0.91)\end{array}$ & $\begin{array}{l}-0.06 \\
(-0.41 \\
\text { to } \\
0.52)\end{array}$ \\
\hline & Rate & $\begin{array}{l}16.82 \\
(10.69- \\
24.40)\end{array}$ & $\begin{array}{l}3.12(2.31- \\
4.09)\end{array}$ & $\begin{array}{l}0.60(0.35- \\
0.95)\end{array}$ & $\begin{array}{l}2.65(1.80- \\
3.84)\end{array}$ & -2703.33 & -17.74 & $\begin{array}{l}-0.96 \\
(-0.98 \\
\text { to } \\
-0.93)\end{array}$ & $\begin{array}{l}-0.15 \\
(-0.48 \\
\text { to } \\
0.35)\end{array}$ \\
\hline \multirow[t]{2}{*}{ Prevalence } & Number & $\begin{array}{l}43705.48 \\
(27722.57- \\
63157.21)\end{array}$ & $\begin{array}{l}1318.75 \\
(975.08- \\
1732.29)\end{array}$ & $\begin{array}{l}2036.37 \\
(1179.82- \\
3207.60)\end{array}$ & $\begin{array}{l}1245.71 \\
(847.95- \\
1794.83)\end{array}$ & -2046.24 & -5.86 & $\begin{array}{l}-0.95 \\
(-0.98 \\
\text { to } \\
-0.91)\end{array}$ & $\begin{array}{l}-0.06 \\
(-0.41 \\
\text { to } \\
0.52)\end{array}$ \\
\hline & Rate & $\begin{array}{l}4.20(2.67- \\
6.10)\end{array}$ & $\begin{array}{l}0.78(0.58- \\
1.02)\end{array}$ & $\begin{array}{l}0.15(0.09- \\
0.24)\end{array}$ & $\begin{array}{l}0.66(0.45- \\
0.96)\end{array}$ & -2700.00 & -18.18 & $\begin{array}{l}-0.96 \\
(-0.98 \\
\text { to } \\
-0.93)\end{array}$ & $\begin{array}{l}-0.15 \\
(-0.48 \\
\text { to } \\
0.35)\end{array}$ \\
\hline \multirow[t]{2}{*}{ Death } & Number & $\begin{array}{l}18068.57 \\
(2.47- \\
90424.02)\end{array}$ & $\begin{array}{l}992.05 \\
(0.20- \\
4225.78)\end{array}$ & $\begin{array}{l}1206.83 \\
(0.15- \\
6695.22)\end{array}$ & $\begin{array}{l}1035.35 \\
(0.30- \\
3983.59)\end{array}$ & -1397.19 & 4.18 & $\begin{array}{l}-0.93 \\
(-0.95 \\
\text { to } \\
-0.92)\end{array}$ & $\begin{array}{l}0.04 \\
(-0.12 \\
\text { to } \\
0.51)\end{array}$ \\
\hline & Rate & $\begin{array}{l}1.97(0.00- \\
9.29)\end{array}$ & $\begin{array}{l}0.63(0.00- \\
2.53)\end{array}$ & $\begin{array}{l}0.09(0.00- \\
0.49)\end{array}$ & $\begin{array}{l}0.51(0.00- \\
2.03)\end{array}$ & -2088.89 & -23.53 & $\begin{array}{l}-0.95 \\
(-0.97 \\
\text { to } \\
-0.94)\end{array}$ & $\begin{array}{l}-0.18 \\
(-0.27 \\
\text { to } \\
-0.06)\end{array}$ \\
\hline \multirow[t]{2}{*}{ DALYs } & Number & $\begin{array}{l}1274643.39 \\
(3006.04- \\
6649597.83)\end{array}$ & $\begin{array}{l}70140.84 \\
(106.72- \\
310324.23)\end{array}$ & $\begin{array}{l}79733.27 \\
(133.61- \\
469598.71)\end{array}$ & $\begin{array}{l}64094.67 \\
(104.71- \\
262432.17)\end{array}$ & -1498.63 & -9.43 & $\begin{array}{l}-0.94 \\
(-0.96 \\
\text { to } \\
-0.92)\end{array}$ & $\begin{array}{l}-0.09 \\
(-0.25 \\
\text { to } \\
0.28)\end{array}$ \\
\hline & Rate & $\begin{array}{l}124.11 \\
(0.29- \\
625.70)\end{array}$ & $\begin{array}{l}41.55 \\
(0.06- \\
178.89)\end{array}$ & $\begin{array}{l}5.88(0.01- \\
34.45)\end{array}$ & $\begin{array}{l}33.63 \\
(0.05- \\
141.34)\end{array}$ & -2010.71 & -23.55 & $\begin{array}{l}-0.95 \\
(-0.97 \\
\text { to } \\
-0.94)\end{array}$ & $\begin{array}{l}-0.19 \\
(-0.33 \\
\text { to } \\
0.01)\end{array}$ \\
\hline
\end{tabular}

Figures 


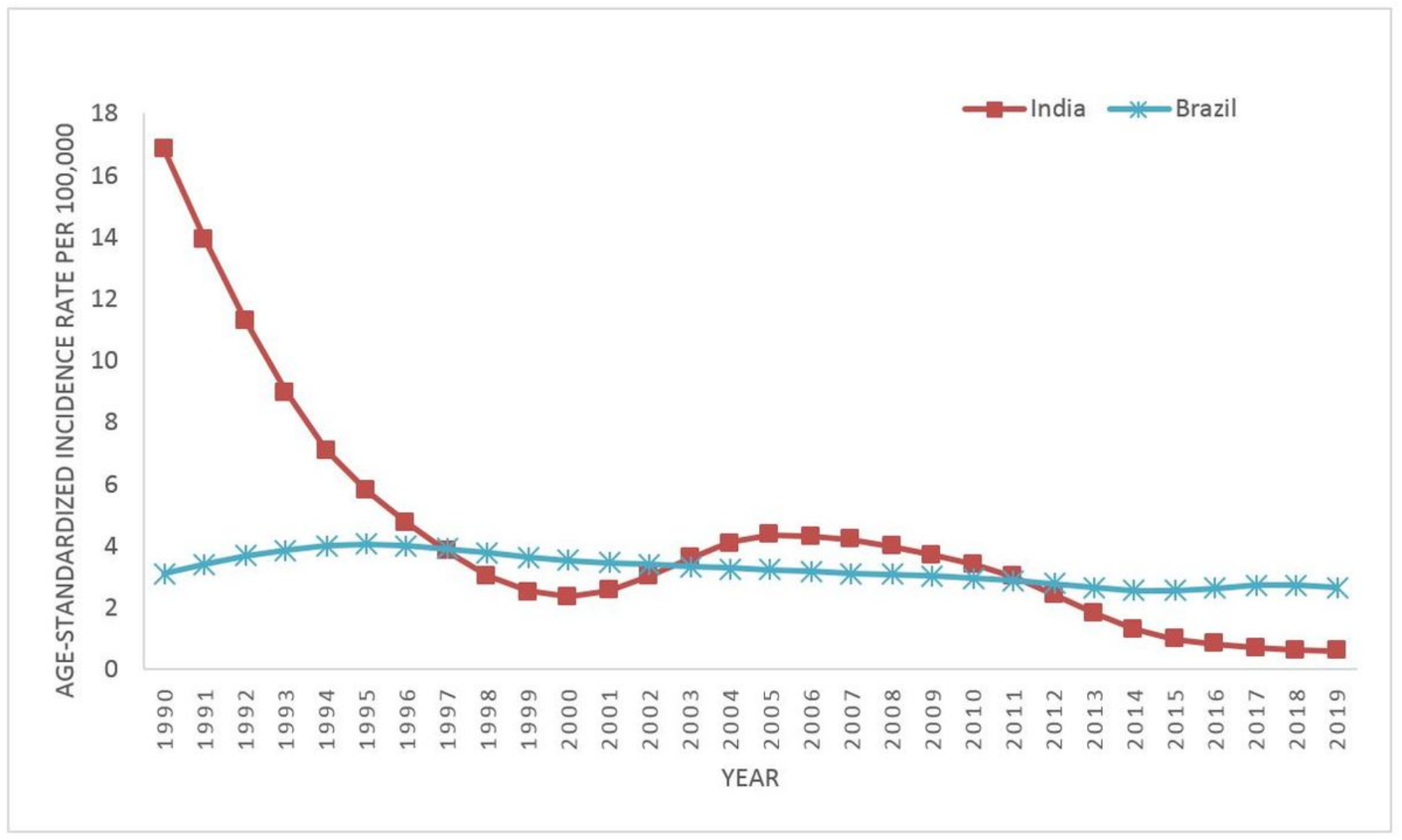

Figure 1

Age standardized Incidence rates for India and Brazil from 1990 to 2019. 


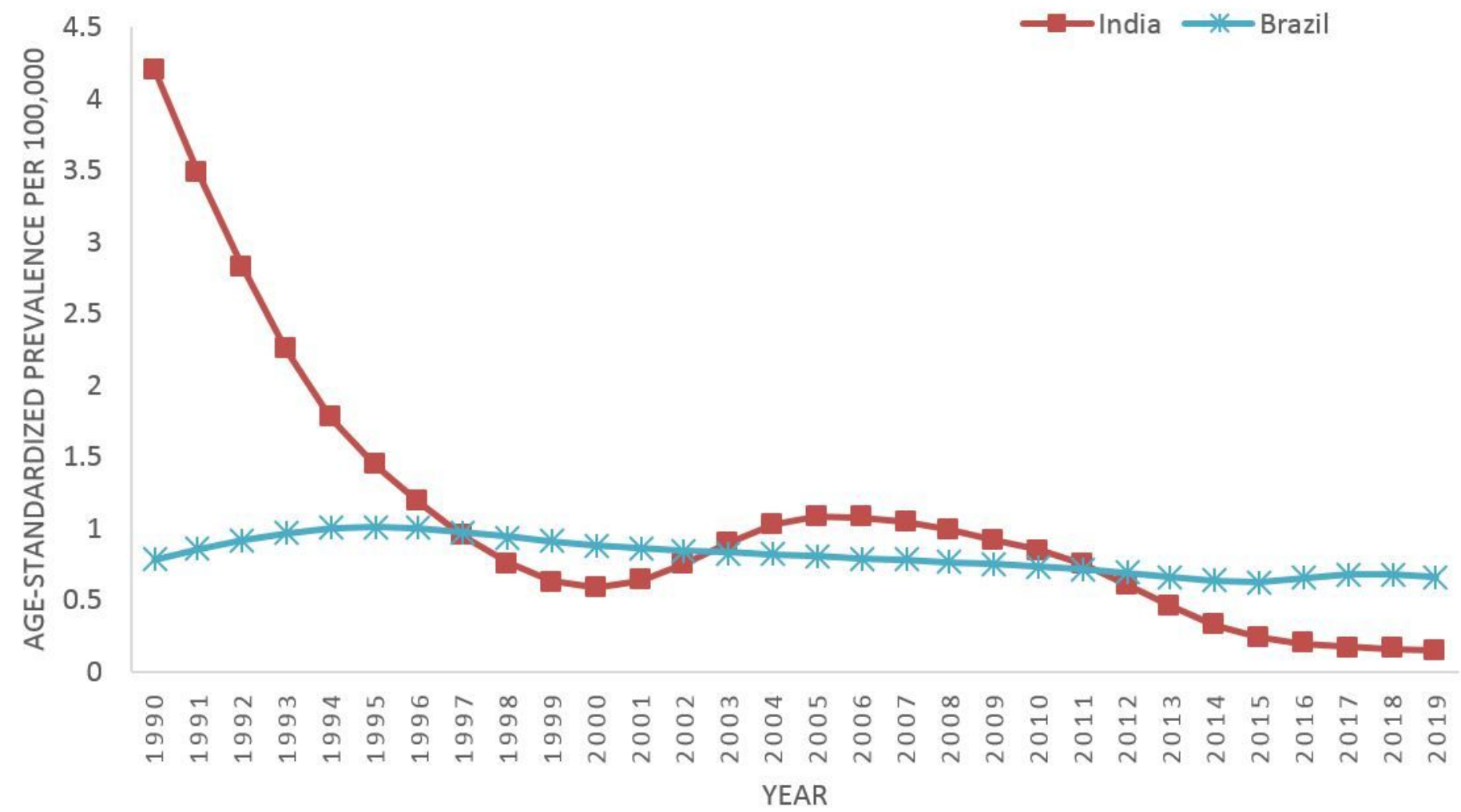

\section{Figure 2}

Age standardized prevalence rates for India and Brazil from 1990 to 2019. 


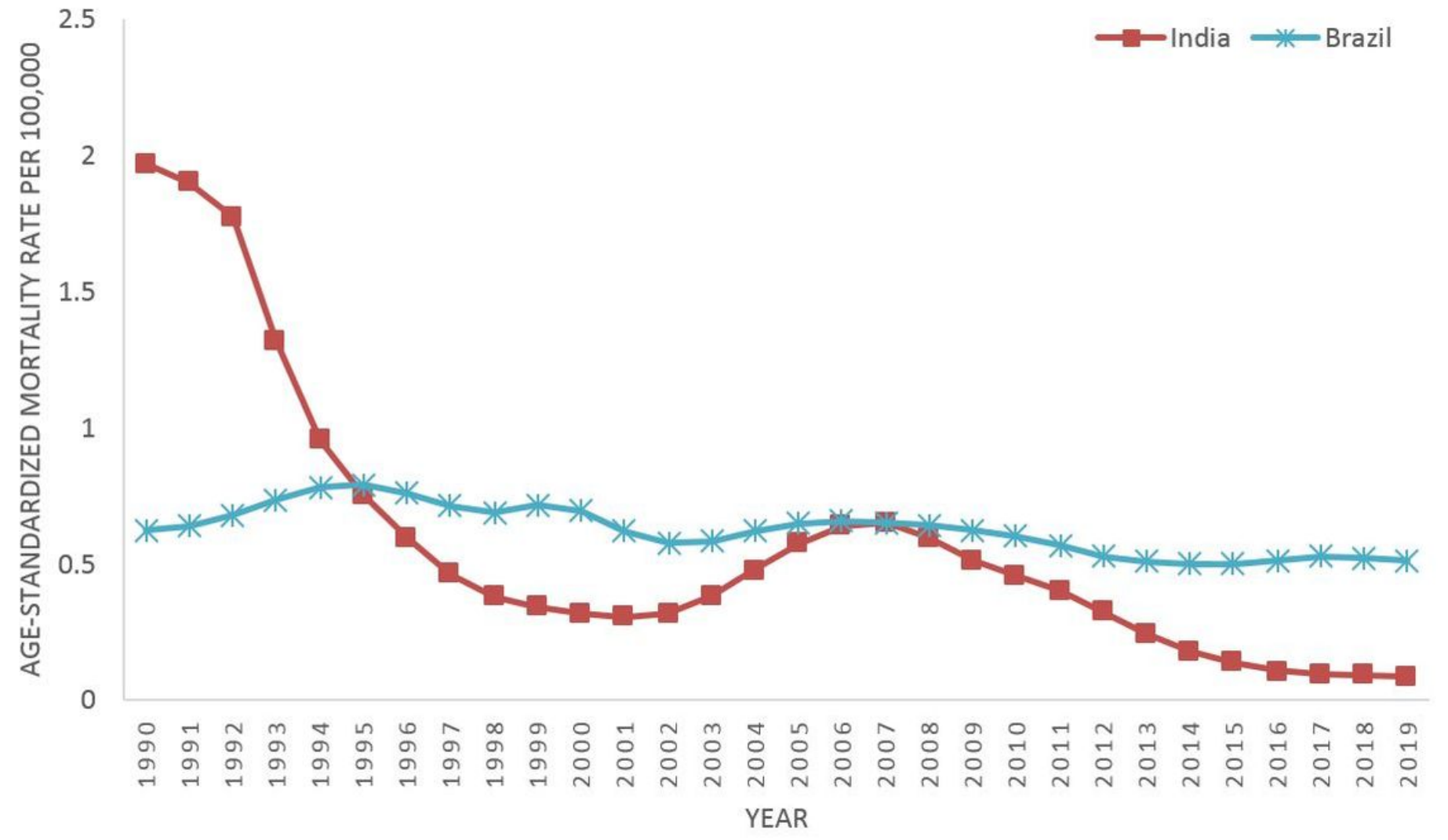

Figure 3

Age standardized mortality rates for India and Brazil from 1990 to 2019. 


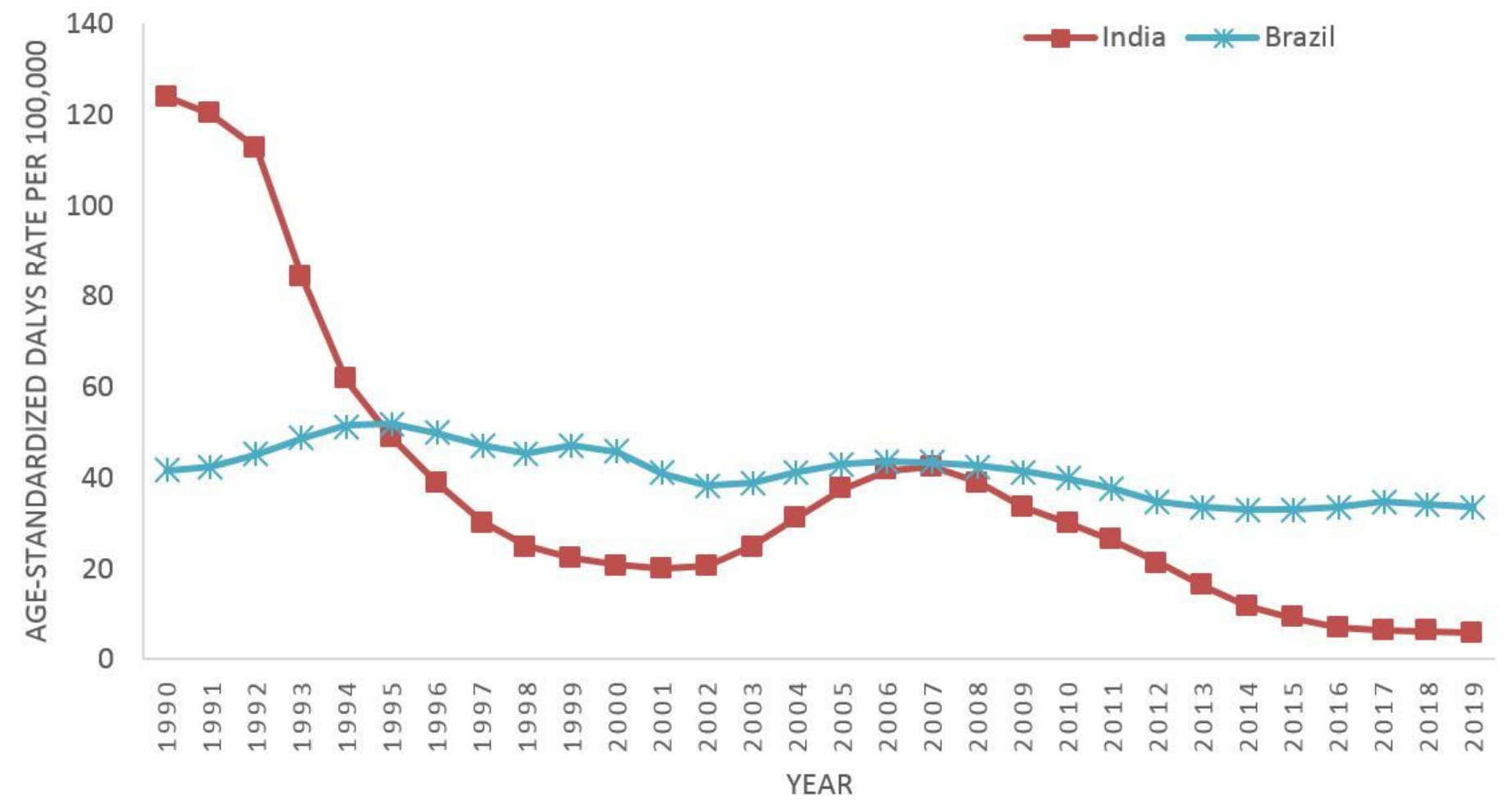

Figure 4

Age standardized DALY rates for India and Brazil from 1990 to 2019.
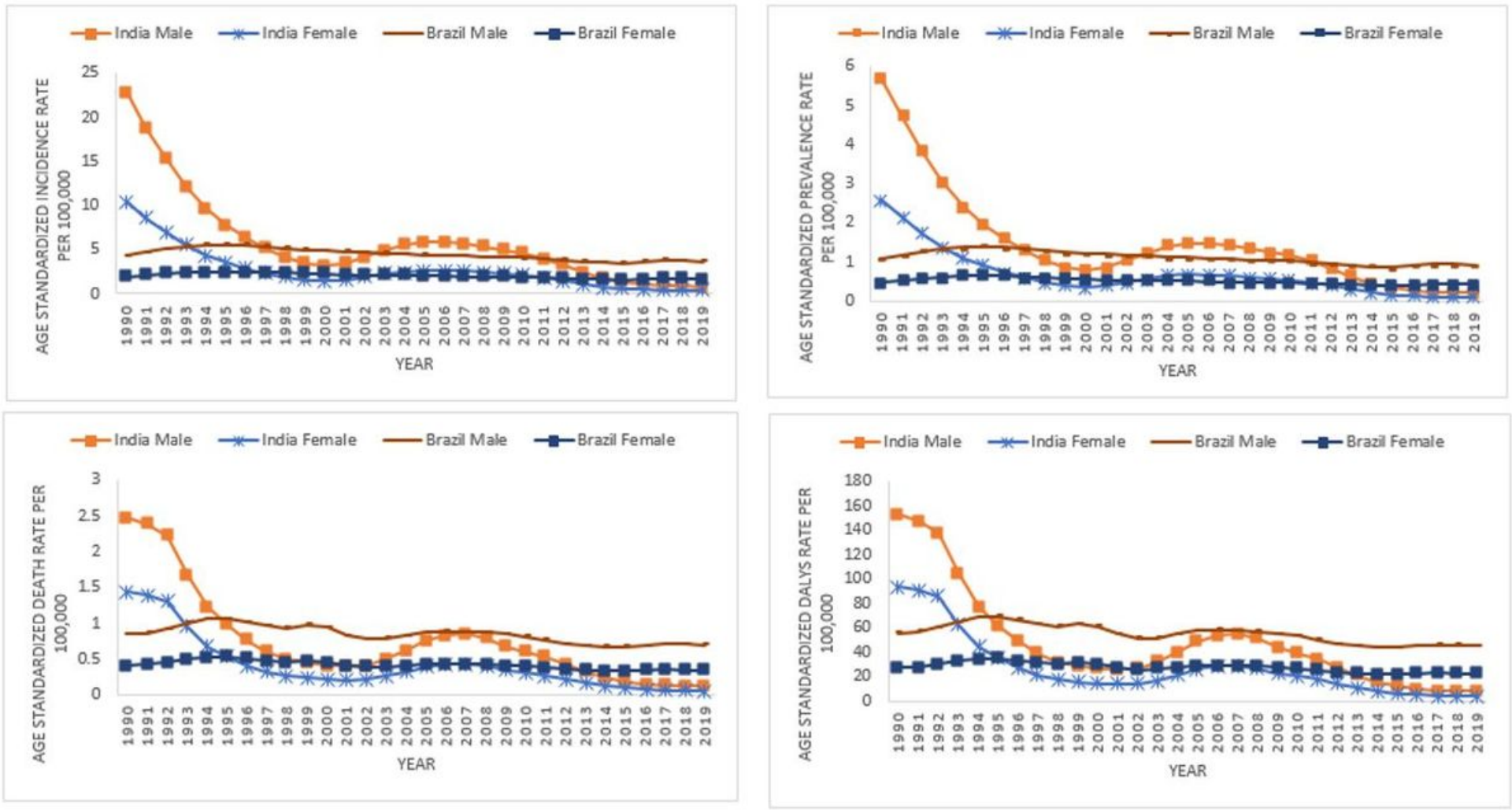

Figure 5 
Gender wise trends of Incidence, Prevalence, mortality and DALY rates of Visceral Leishmaniasis for India and Brazil ; 1990 to 2019.
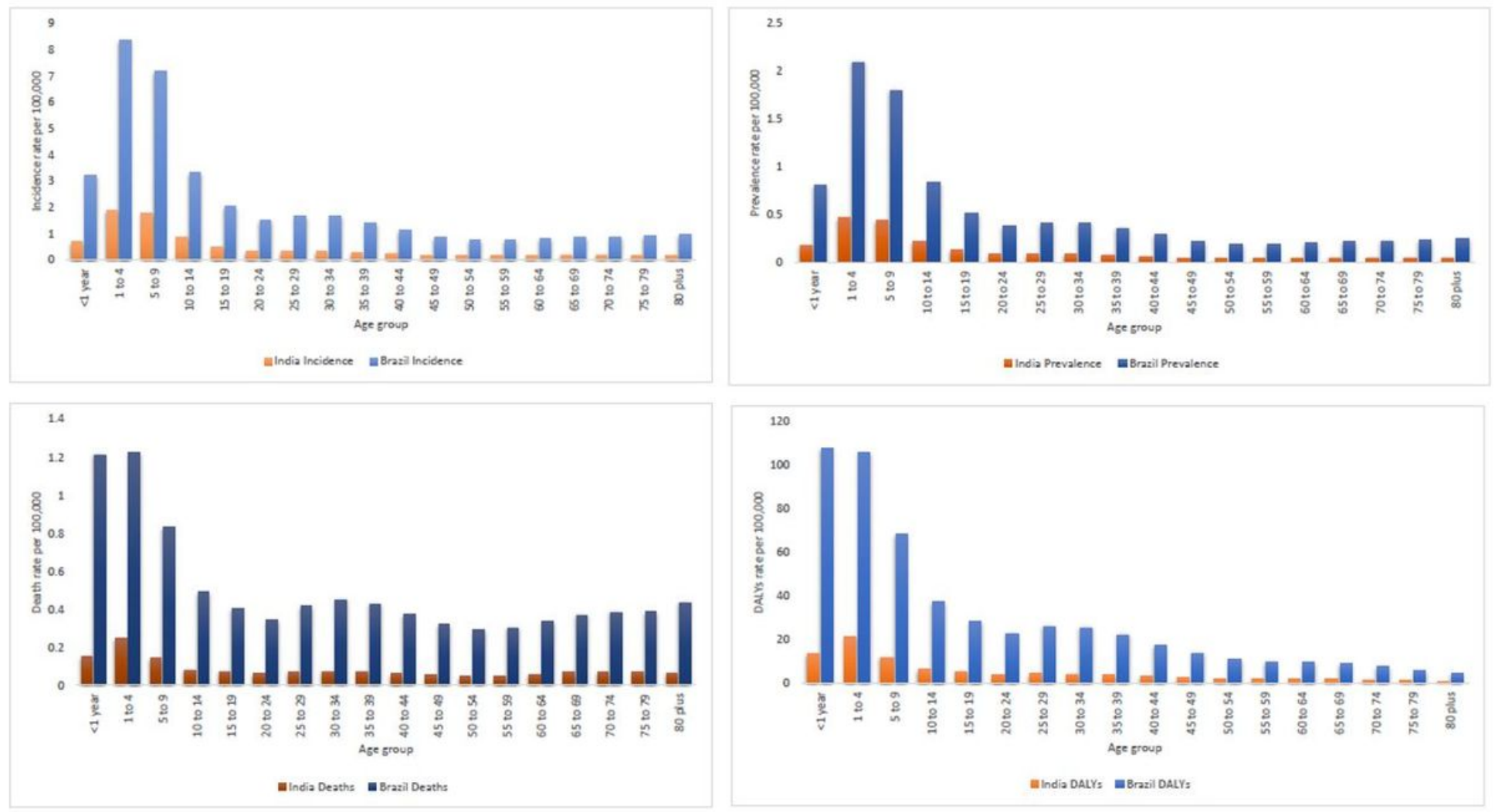

\section{Figure 6}

Age wise distribution of Incidence, Prevalence, mortality and DALY rates of Visceral Leishmaniasis for India and Brazil in 2019. 